\title{
Can and Should Social Competence be Taught to Engineers?
}

\author{
http://dx.doi.org/ijep.v1i3.1811 \\ P. Lappalainen \\ Aalto School of Science, Aalto, Finland
}

\begin{abstract}
The traditional focus in engineering syllabi on technical abilities has been well substantiated by the type of expertise required in industrial processes. However, the emerging requirements in industrial operating environments necessitate a more personal configuration of competencies facilitating both intrapersonal and interpersonal processes at workplace. The concomitant reform of engineering education to incorporate social competence into the technical education calls for a revision of pedagogy, as the traditional instruments applied in the dissemination of substance knowledge and technical skills provide little support for leveraging students' social skills.
\end{abstract}

This article discusses the learnability of socio-emotional abilities and reviews their most fundamental and pertinent skills. The results from a quantitative research conducted to identify predictors of social competence are reported and the implications on engineering pedagogy examined. The proposed methodology for teaching social skills in the engineering classroom setup constitutes collaborative learning, self-management techniques, and teacher immediacy.

Index Terms - emotional intelligence, emotive communication, engineering curriculum, social competence.

\section{TREnds Altering ComPetence ReQUiREMENTS IN ENGINEERING}

Traditionally, the engineering education model has been founded on specialization, which has been merited as the driving force enabling technological advancement and fuelling economic growth. Ironically, however, specialization is claimed to have turned into an unintended impediment to sustaining societal land industrial development. [1] Conversely, recent research on work success has announced the advent of social and emotional skills and the related interpersonal communication competencies as organizational success factors. [2] A relationship between certain personal competencies, often conceptualized as emotional intelligence, and organizational productivity as well as individual work and overall life success has been firmly established. [3], [4]

The growing concerns about the inadequate and too narrowly oriented engineering education evidence the controversy between specialized content and broader orientation towards the societal context, and demands for closing the gap between engineering science and engineering practice call for concrete measures in university curricula. [5] Membership of engineering teams, networks and communities increasingly require not only substancerelated, hard core technological expertise but also socalled soft skills enabling engineers to integrate thinking, feeling and behaviour while pursuing their professional goals. [6]

The revision of higher engineering education should therefore aim at transforming the narrow focus and depth of knowledge in a single area into an extended avenue towards full-scale professional expertise. [7] Such competence is known to allow individuals to use emotions advantageously to achieve desired outcomes, thereby having become a business imperative affecting employee productivity, loyalty, engagement and contribution. [8]

The concomitant reform of engineering education to incorporate socio-emotional competence into the technical education calls for a revision of engineering pedagogy, as the traditional instruments applied in the transfer of substance knowledge and technical skills provide little support for the enhancement of students' social skills.

This article begins with a report of results from a quantitative doctoral study striving to identify predictors of effective leadership in engineering industries. Having established the crucial role of social competence in engineering, the article moves on to discuss the learnability of socio-emotional abilities and reviews their most fundamental and pertinent skills. This article concludes with methodology proposed for teaching social skills in the engineering classroom setup, constituting student selfmanagement techniques and teacher immediacy.

\section{RESEARCH FRAMEWORK}

The overall research problem of this study is: How to equip managers operating in engineering industries with skills meeting industrial needs? The overall problem can be broken down to three more specific research objectives:

1. First, the work sets out to determine what makes leaders successful.

2. Second, emotive communication is conceptualized and operationalized and a related communication model delineating its most essential cornerstones is designed.

3. Third, pedagogy is pursued to identify means of learning, developing and teaching emotional skills and social competence in engineering.

Various managerial attributes (traditional intelligence, personality, communication based on emotional intelligence) are placed at the kernel of this research to establish correlation between managerial qualities and their perceived subordinate impact. This work revolves around the hypothesis that managerial social competence affects subordinate performance. To corroborate this, quantitative research was initiated to identify traits or abilities that pre- 


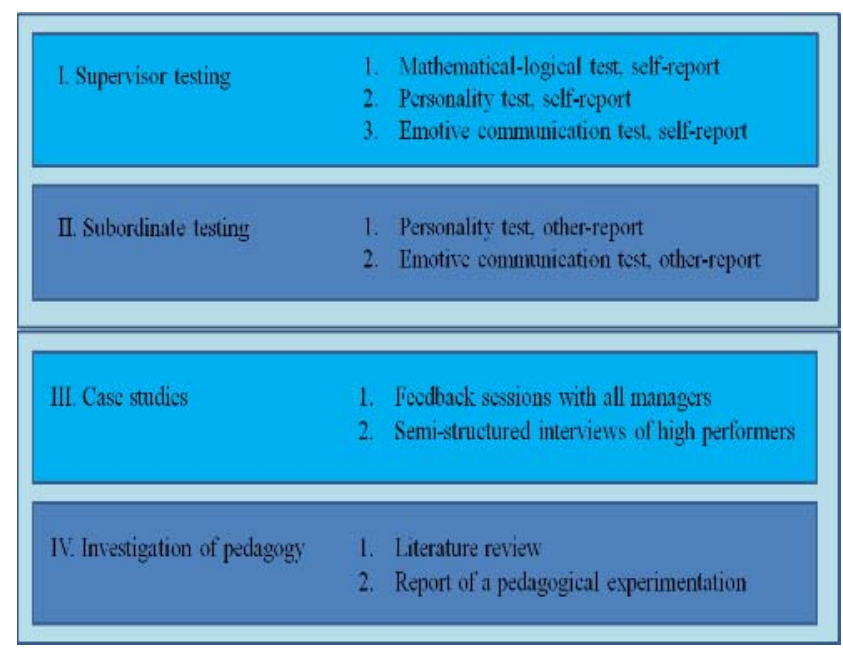

Figure 1. The research design of the present study.

TABLE I.

THE NUMBER OF TESTS RUN WITHIN THE SAMPLE.

\begin{tabular}{|l|c|c|c|c|c|}
\hline & $\begin{array}{c}\text { Supervi- } \\
\text { sors }\end{array}$ & $\begin{array}{c}\text { Subordi- } \\
\text { nates }\end{array}$ & $\begin{array}{c}\text { Superv } \\
\text { tests }\end{array}$ & $\begin{array}{c}\text { Subord } \\
\text { tests }\end{array}$ & $\begin{array}{c}\text { To- } \\
\text { tal }\end{array}$ \\
\hline Finance & 22 & 74 & 66 & 148 & 214 \\
\hline Forest & 9 & 28 & 27 & 56 & 83 \\
\hline Construction & 7 & 32 & 21 & 64 & 85 \\
\hline ICT & 2 & 7 & 6 & 14 & 20 \\
\hline Total & 40 & 141 & 120 & 282 & 402 \\
\hline
\end{tabular}

dict effective leadership. The research design aiming at meeting the research objectives is described Figure 1.

The preliminary population comprised of 40 managers operating in four different fields: finance, forestry, construction and ICT. Subordinate views on the abilities of the 40 managers were collected from 141 subordinates. As each manager took 3 different self-report tests and their subordinates 2 other-reports, a total of 402 tests were run within this empirical effort. Table I illustrates the contribution of each participating organization in the study.

\section{A. Findings from the quantitative research}

Altogether 21 variables were investigated in connection with each respondent's traits and abilities. As self-report objects, performance in mathematical-logical problemsolving and communication based on emotional intelligence were surveyed. The third test, a personality index offered self-report scores on 14 personality dimensions: focusing, competition, leadership, inspiration, sociability, empathy, reliance, orientation, perception, decisionmaking, ambiguity-change, optimism and self-image. In addition, gender and age were also reported and examined by means of correlation analysis. The scores of the population can be found in Appendix 1.

Results from the empirical research that are statistically significant at the 0.05 level (correlations can be found in Appendix 2) indicate that

1. dimensions of the personality index and the Emotive Communication self-report are more effective predictors of subordinate satisfaction than the mathematical-logical test.

2. mathematical-logical intelligence correlate negatively with subordinate ratings.
3. self-reported level of optimism correlates with subordinate satisfaction.

4. self-reported emotive communication ability correlates with subordinate perceptions.

5. mathematical-logical intelligence correlate with competition motive.

6. variation in test performance cannot be assigned to gender or age.

7. orientation towards either analytical or creative thinking does not contribute to subordinate perceptions.

8. a manager's self-image does not correlate with subordinate evaluations.

9. the level of a manager's sociability correlates with the overall impression of his/her emotive communication ability.

10. a manager's level of reliance on others negatively correlates with his/her decision-making and attitude toward change.

In sum, the results demonstrate that mathematicallogical intelligence does not predict the ability to lead others and manage teams. In contrast, such dimensions of personality as sociability and optimism explain for variance in subordinate perceptions. Also, high scores in emotive communication correlate with positive subordinate perceptions, inviting us to further implore and understand the role of socially intelligent interaction at workplace.

\section{EMOTIVE COMMUNICATION ABILITY AS AN EMERGING REQUIREMENT}

Socio-emotional competence in this article denotes such intrapersonal and interpersonal traits and abilities defined in Ref [9] as self-awareness, self-management, selfmotivation, social awareness, and social skills. This article is focused on those sub-dimensions of social competence that provide the prerequisites for emotive communication ability, which according to recent research is as an asset in working life interaction. Emotive communication is operationalized here as emotional regulation, empathy, assertion and inspiration, hypothesized as the most pertinent characteristics of effective workplace interaction.

Emotional regulation or control as an essential component of emotional intelligence allows the individual to analyze, plan, anticipate and control his interaction. [10] Such reflective ability is an instrument in playing down negative emotions and in fortifying positive ones, contributing to effective self-leadership, which seems to correlate with team productivity. [11], [12] Furthermore, individuals high on emotional control are likely to be good nonverbal actors, with the ability to pose emotions on cue and adjust their nonverbal behaviour in a way that fits in to different social situations. In contrast, ill-timed or excessive emotional displays are typically interpreted as unauthentic or inappropriate. [13]

Empathy is a primary cornerstone in genuine and meaningful interaction, preconditioning that the interlocutors be willing to construe their counterparties and each other's point of view. Empathy, both cognitive and emotional, is a central dimension impacting leader behaviour in interaction with others; it contributes to the ability to apprehend the state of mind of those around and to take into account the reasons and logic behind the interlocutor's feelings. Empathy comprises of factors such as social self- 
confidence, sensitivity and flexibility, facilitating true dialogue. [14], [15], [16], [17]

Assertion contributes to so-called power language that is essential in bolstering a confident image and eliciting trust in others. [18] As its key constituents, articulation, errorless message delivery and verbal directness bear relevance through their association with speaker confidence, eloquence and credibility. People high on argumentativeness are firm, forceful and capable of defending their position, and what is more, not afraid of confrontations. [19], [20]

Inspiration was included in the research scope as it became evident that elements related to inspiration and ability to motivate others needed to be underscored. As an example, communication signaling enthusiasm contributes to trust build-up in teams. [21] Similarly, leader positivity and optimism, both factors of inspiration, tend to induce cognitive trust in the leader and perceptions of leader effectiveness. [22]

Figure 2 depicts the emotive communication model that strives to convey the elements and make-up of effective workplace interaction in engineering. Emotive communication ability is divided into intrapersonal and interpersonal levels. On the intrapersonal level, self-regulation based on self-awareness serves as the prerequisite for effective communication behavior. On the interpersonal level, successful communication skills are materialized by and manifested as assertion, empathy and inspiration.

\section{A. Learnability of Social Competence}

It is recent understanding that expertise does not necessarily stem from innate abilities but instead, deliberate practice is an instrument helping build experts - even in social competence. Persistent practice will either help improve the skills students already have or extend the reach and range of their skills. [23]

The central question in the revision of higher education to incorporate soft skills is whether social competences can be taught. The key acumen has for long been the understanding that human beings are endowed with abilities for emotional and non-verbal exchange already at infancy when they display synchronization, reciprocity, behavioural dialogue, accommodation, coordination, and attunement. [24] Recent research and field experiments, however, strongly argue in favour of the learnability of social competence, providing evidence that it is possible to promote emotional intelligence and social skills through education and training. [25]

According to a popularly cultivated belief, those working in highly technical fields possess inferior emotional intelligence skills, and although some researchers [26] have detected slightly lower scores in engineers' EI abilities, they claim it can be accounted for by the infrequent training or lack of reward for social competence available in engineering industries. Encouragingly, scores on the emotional intelligence quotient are detected to increase as a result of the individual's psychological maturity, as a result of the experiences he is confronted with, or as a result of the training attended. [27]

Others [28] have found support for these claims, maintaining that EQ continues to develop through the entire lifetime, especially if individuals subject themselves to feedback on their dysfunctional behaviour.

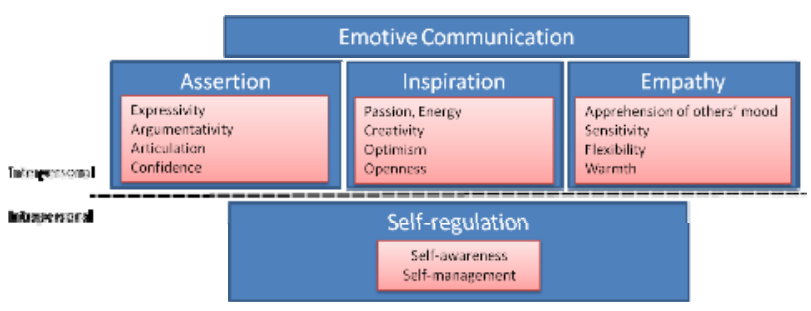

Figure 2. Emotive communication ability as part of the professional engineering skills set.

A wealth of evidence indicates that emotional competence can be enhanced, with effective benefits in personal and interpersonal functioning [29], urging university faculty to identify methodology for teaching social competence.

\section{Pedagogy for TEAChing Social Competence}

Several paradigm shifts in engineering education are altering the demands posed on engineering pedagogy. If the trend towards accentuation of working life competences serves as the first emerging requirement, a second paradigm shift can be detected in the transition of focus from learning outcomes to the learning process, moving education from didactic to more student-centred approaches such as cooperative and experiential learning. [30], [31] This serves the aim of reducing the traditional emphasis on knowledge transmission while encouraging students to understand, investigate, and solve problems. [32]

Third, as personal attributes, behaviours and traits are becoming acknowledged as factors decisive in recruitment and career advancement, universities are challenged to move away from the dissemination of facts to a more holistic education securing a wider configuration of student competencies. The traditional education that demands memorisation and application of course material has turned graduates into competent problem-solvers that possess a good memory, but as the professional skills set is changing, we urge the incorporation of socio-emotional competence. [33] The section below will propose methodology for facilitating and supporting the development of engineers' socio-emotional skills in the classroom.

\section{A. Student Empowerment and Self-Management}

To secure heterogeneous teams in industry, skilling needs to foster diversity and differentiation. The institutional culture should therefore be upgraded by questioning the traditional role of the teacher, the formality of the classroom, and the teacher-centred lecturing style. Moving away from compliance-driven towards diversity-oriented teaching necessitates an enlargement of teacher repertoires of classroom management techniques. This cannot be achieved by authoritarian or modelling teacher roles but instead the student should be placed at the centre to promote self-directed learning. [34] Such student-centred learning can materialize through peer assistance, support, and mentoring which have been identified as means of encouraging students to take responsibilities extending beyond their own specific field to promote active rather than reactive learning. [35]

Further, self-management strategies enhance individuals' ownership and control and increase personal responsibility and accountability for outcomes. An empowering classroom culture promotes self-knowledge by liberating students to explore themselves as learners. The corner- 
stones of empowering educational philosophies constitute trust, communication and participation, which elicit commitment. More concretely, verbal persuasion serves as the means of communicating to students the teacher's faith in their ability and competency to perform the given tasks. Such interaction not solely redistributes power in the classroom but allows students to actively create their power. Empowering verbal communication is multileveled, honest, constructive, and places emphasis on active listening and reception of student feedback. [36]

A permissive or free environment also rids students from fear of judgment and rejection, allowing them to feel free to put forth ideas and questions knowing that the lecturer will not react through rejection, derision, blame or authoritarian injunctions. It is of the essence that the teacher models behaviour that is nonjudgemental, cooperative, empathetic, and spontaneous. [37]

Most importantly, empowering classroom strategies extend beyond traditionally dominant pedagogies that are scientifically, empirically and rationalistically oriented. Instead of valuing an image of strength, empowering techniques welcome the acknowledgement and expression of one's feelings and the acceptance of those of others. However, this holistic stance of moving away from the relegation and disparagement of feelings towards appreciation and exploration of personal feelings does not preclude the more rational dimensions of learning.

Active experimentation and experiential education facilitate learner progression to empowerment. The process from the concrete classroom experience to reflected observation all the way to abstract conceptualization helps the learners formulate their own conceptions about the meaning and relevance of the data available. [38]

Furthermore, the type of feedback cultivated, and more specifically, the choice between direct and indirect feedback in instruction impacts the extent of student empowerment. Direct feedback refers to the provision of the correct answer, whereas in indirect feedback the teacher signals, e.g. by means of an underline, circle or other mark, that an error has been made. Research indicates that in general, indirect feedback is preferable as it forces the learner to engage in guided learning and problem-solving. Such reflective learning processes help build skills as an independent self-corrector. [39] However, too ambiguous a feedback may confuse learners who require more imperative and explicit commentaries in order to achieve substantive revision to their work. [40]

Finally, empowered students are granted with the privilege of choice. Instead of following the syllabus precisely, students should be provided with freedom to exercise choice in applying assignment specifications and operational classroom rules. Such freedom seems particularly important for those already holding jobs as they are keen on experimenting with the expertise they have gained at work. [41]

\section{B. Teacher Immediacy and Perceived Caring}

As behaviour alteration techniques the teacher could consider methods that reward positive conduct instead of punishing negative ones. E.g. positive teacher-student relationship and personal student responsibility are known to entail positive outcomes in the classroom. Similarly, immediate or deferred reward from teacher and others, as well as peer modelling will entail positive outcomes through a more collaborative classroom atmosphere. These prove particularly feasible in communication education where the substance matter is so contextual that student responses can rarely be judged as completely wrong. Finally, bolstering of positive self-esteem has a way of reinforcing positive student performance. [42], [43]

Face-to-face instructional classroom methods make a difference in students' learning outcomes as student learning and short-term information recall intensify when their teacher communicates positive regard to the students. [44] Moreover, students have been reported to learn most from teachers that are warm, friendly, immediate, approachable, affiliative, and able to foster close personal relationships. In brief, a curvilinear relationship exists between teacher immediacy and students' cognitive, affective and behavioural learning. [45], [46]

Resultatively, one of the pivotal pedagogic qualifications for any teacher promoting more effective learning outcomes in the classroom is communication, serving, among others, as a means of bolstering student certainty through application of so-called power language. Certain forms of language generate inferences impacting impression formation, resulting in judgments regarding the pedagogue's competency and intellect. Speech devoid of hedges, intensifiers, deictic phrases and hesitations enhance teacher credibility and positively affect classroom climate and learning. [47]

Further, moderate immediacy behaviours promote closeness with students, thereby reducing psychological distance between the instructor and the students, overall sensory stimulation, and promoting liking. Teachers can largely benefit from nonverbal immediacy behaviours as relational messages are best conveyed nonverbally, which leaves the verbal channel available for messaging content. Such nonverbal behaviours include proxemics (distance), haptics (touch), vocalic (vocal expressiveness), kinesics (facial and body movement), eye contact, chronemics (time spent with students), physical appearance and attire. [48]

Similarly, a teacher's communication variables play a role in leveraging empowerment in the classroom. Relational communication variables such as active listening, openness, constructive feedback, trustworthiness, credibility and immediacy influence students' task motivation and personal involvement. They also promote the alignment and adoption of common values in the classroom, reducing feelings of powerlessness and intimidation while fostering feelings of qualification, meaningfulness and selfconfidence, which are preconditions in education subjecting students to vulnerability through public presentations and oral delivery of their own products. [49]

Interestingly, teacher communication correlates also directly with perceived learning. A strong, causal association between the teacher immediacy and student learning has been identified. The link between nonverbal immediacy and affective learning outcomes has already previously been established through student self-reports of cognitive gains which have been found indicative of results acquired through more direct forms of assessment, as students commonly have a good sense of what they have learned. However, a comparative study of different cultures [50] found that in highly immediate cultures the expectations for immediate teacher conduct are high and 
consequently the violation of those expectations by less immediate conduct may be detrimental to cognitive learning. What is more, in less immediate cultures where expectations for immediacy are low, more immediate teacher behaviour, although violating the expectations, may have strong positive effects on cognitive learning. This bears significant relevance to Finland which represents a low-expressive and nonimmediate culture where teachers have been reported to be less immediate than in any other culture. The inclusion of individual nonverbal immediacy through e.g. movement, gestures, facial expression, and in particular vocal variety, eye contact and smile in Finnish teacher training may entail clear benefits for university students.

Such immediacy is critical in modelling social competence in the classroom. To become accustomed to expressing themselves, students need regularly to be subjected to classroom interaction as the only way to learn to communicate is by communicating. [51] To voluntarily and willingly perform in front of the others, students need to feel secure in the group, which is one of the key challenges for the pedagogue. For this, teachers need to understand that human interaction is motivated on the individual level by the avoidance of shame and pursuit of appreciation. [52] As another immediacy-derived solution nurturing a safe atmosphere allowing students to move away from self protection, research proposes perceived caring on the part of the lecturer.

The construct of perceived caring draws from three factors in teacher behaviour: empathy, understanding, and responsiveness. Empathy manifests itself as concern for student wellbeing; understanding implies the teacher's ability to comprehend and respect student views, and responsiveness refers to the teacher being attentive and listening to the students and reacting to student needs and problems promptly.

Perceived caring on the part of the teacher, also labelled as good will or positive intent toward students, entails benefits in terms of positive learning outcomes. Teacher behaviour that signals a positive attitude towards student well-being and their best interest influences learning both on the affective and cognitive levels. Nonverbal immediacy, a concept describing positive evaluation of or affect to students, results in higher rate of class attendance and recall of information, decrease in learning loss, improved motivation and more attentive listening. [53], [54], [55], [56] Interestingly, it also tends to decrease student likeliness to generate compliance resistance strategies and predicts strongly classroom interaction and communication. [57] Teacher immediacy also impacts student ratings of overall instruction quality, which is an important consideration especially when regarding students as consumers of education. [58]

These findings may cause anxiety in those having realized in their daily teaching routines how unrealistic it is to demand teachers to have positive affects to all their students at all times. For them it will be comforting to know that it is not the caring itself that counts, rather it is the perception of caring that is critical. [59]

\section{CONCLUSION}

This article set out to further establish the role of socioemotional skills in engineering communities. More specifically, it aimed to provide a set of elements fundamental

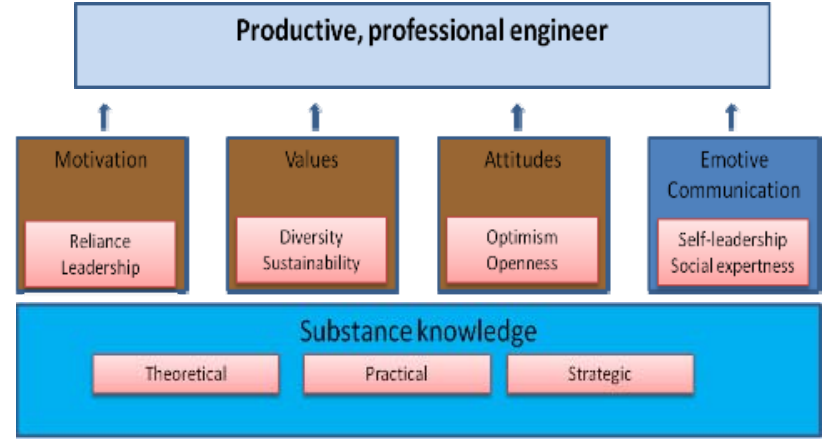

Figure 3. The professional competency of engineers.

for the education of engineers that meet today's industrial competence needs. In particular, the objective was to further the development of engineering students' social competence. The framework described supports the enhancement of emotive communication ability by addressing its most pertinent skills, that is, emotional regulation, empathy, assertion, and inspiration.

Figure 3 showcases how emotive communication fits into the overall professional competency of engineers. This skills-oriented model does not address such personality traits as sociability or extroversion, following the hypothesis that in communication education, focus should be placed more on learnable skills than on fixed personality traits.

Self-evidently, substance knowledge constitutes the foundation of an engineer's professional competence, embracing theoretical, practical or technical, and strategic or conceptual knowledge. [59] Motivation serves as the link between substance knowledge and interaction skills, drawing from reliance and leadership motifs, and explaining for variance not only in leader outcomes but also in the extent to which the individual engineer succeeds in developing and learning social skills pertinent to interaction. As pedagogy appropriate for disseminating social competence we propose student empowerment and teacher immediacy, calling for subsequent measures in teacher training to secure teacher competence in the field of socio-emotional abilities.

\section{REFERENCES}

[1] Akay, A.: A renaissance in engineering PhD education. European Journal of Engineering Education, 33(4) 2008, 403-413. http://dx.doi.org/10.1080/03043790802253475

[2] Groves, K.: Linking Leader Skills, Follower Attitudes, and Contextual Variables via an Integrated model of Charismatic Leadership. Journal of Management, 31(2), 2005, 255-277. http://dx.doi.org/ 10.1177/0149206304271765

[3] Fox, S. \& Spector, P.: Relations of emotional intelligence, practical intelligence, general intelligence, and trait affectivity with interview outcomes: it's not all just 'G'. Journal of Organizational Behavior, 21, 2000, 203-220. http://dx.doi.org/10.1002/(SICI)10991379(200003)21:2<203::AID-JOB38>3.3.CO;2-Q

[4] Goleman, D. \& Boyatzis, R. \& McKee, A.: Primal Leadership. The Hidden Driver of Great Performance. Harvard Business Review, Dec 2001, 42-41.

[5] Woollacott, L.: Validating the CDIO syllabus for engineering education using the taxonomy of engineering competencies. European Journal of Engineering Education, 34(6), 2009, 545-559. http://dx.doi.org/10.1080/03043790903154465

[6] Emilsson, U.M. \& Lilje, B.: Training social competence in engineering education: necessary, possible or not even desirable? An explorative study from a surveying education programme. European Jour- 
nal of Engineering Education, 2008, 33(3), 259-269. http://dx.doi.org/10.1080/03043790802088376

[7] Newswander, L. \& Borrego, M.: Using journal clubs to cultivate a community of practice at the graduate level. European Journal of Engineering Education, 2009, 34(6), 561-571. http://dx.doi.org/ $\underline{10.1080 / 03043790903202959}$

[8] Sudhakar, B., Patil, Sujit M.: Measuring up. Communication World, Sep/Oct2006, Vol. 23, Issue 5, 32-35.

[9] Bar-On, R.: The Bar-On model of emotional-social intelligence. Published in Bernandez-Berrocal, P. \& Extremera, N. (Guest Eds), Special Issue on Emotional Indiligence. Psicothema, 17, 2005.

[10] Rouhiainen-Neunhäuserer, M.: Johtajan vuorovaikutusosaaminen ja sen kehittyminen (Translated by P.L. Managerial interaction ability and its development). Jy-väskylä studies in humanities, 128, 2009.

[11] Simström, H.: Tunneälytaidot ikäjohtamisessa (Translated by P.L.: EI skills in age management). Dissertation series, Tampere University. 2009.

[12] Åhman, H.: Oman mielen johtaminen. (Translated by P.L.: Self-management) HUT, Dissertation Series 2003/12.

[13] Groves, K.: Linking Leader Skills, Follower Attitudes, and Contextual Variables via an Integrated Model of Charismatic Leadership. Journal of Management, 31(2), April 2005, 255-277. http://dx.doi.org/10.1177/0149206304271765

[14] Johnson, J., Cheek, J., Smither, R.: The structure of empathy. Journal of Personality and Social Psychology, 1983, 45 (6), 1299-1312. http://dx.doi.org/10.1037/0022-3514.45.6.1299

[15] Rouhiainen-Neunhäuserer, M.: Johtajan vuorovaikutusosaaminen ja sen kehittyminen (Translated by P.L. Managerial interaction ability and its development). Jy-väskylä studies in humanities, 128, 2009.

[16] Goleman, D. \& Boyatzis, R. \& McKee, A.: Primal Leadership. The Hidden Driver of Great Performance. Harvard Business Review, Dec 2001, 42-41.

[17] Lynn, A.: Finding Employees with High Emotional Intelligence. AMACOM Books, USA, 2008.

[18] Areni, C. \& Sparks, J.: Language Power and Persuasion. Psychology and Marketing, 22(6), 2005, 507-525. http://dx.doi.org/10.1002/mar.20071

[19] Pöllänen, K.: Finnish Leadership in Transition. Svenska Handelshögskolan, Dissertation Series, 2008.

[20] Eelen, G.: A Critique of Politeness Theories. Manchester, St. Jerome Publishing, 2001.

[21] McNair, L.; Paretti, M.; Davitt, M.: Towards a Pedagogy of Relational Space and Trust: Analyzing Distributed Collaboration Using Discourse and Speech Act Analysis. IEEE Transactions on Professional $\begin{array}{llll}\text { Communication, } & 53(3), & \text { Sept } & 2010 .\end{array}$ http://dx.doi.org/10.1109/TPC.2010.2052857

[22] Norman, S.; Avolio, B.; Luthans, F.: The impact of positivity and transparency on trust in leaders and their perceived effectiveness. The Leadership Quarterly, 21, 2010, 350-364. http://dx.doi.org/ 10.1016/j.leaqua.2010.03.002

[23] Ericsson, A.; Prietula, M.; Cokely, E.: Managing for the long term. The Making of an Expert. Harvard Busi-ness Review, July-August 2007, 115-121.PMid:17348175

[24] Saarinen, E. \& Hämäläinen, R.: The Originality of Systems Intelligence. Published in Hämäläinen, R. \& Saarinen, E. (Eds): Essays on Systems Intelligence. Aalto University, Ssytems Analysis Laboratory, 2010.

[25] Kultanen, T.: Tunneälytaidot. Esimiesvalmennus ICT-alalla. Sosiaalisen innovaation suunnittelu, toteutus ja arviointi. (Translated by P.L.: Emotional Intelligence skills. Leader training in ICT. Planning, implementation and evaluation of social innovations) Tampere University, Dissertation series 2009/1.

[26] Duse, D.-M.; Duse, C.S.; Deac, C. : Emotional Intel-ligence an Important Part of the Teaching Qualification in Engineering Education. SEFI conference paper. Rotterdam 2009.

[27] Duse, D.-M.; Duse, C.S.; Deac, C. : The Quality of Academic Staff: Student Assessment versus an evaluation of the emotional intelligence. SEFI conference paper, Rotterdam 2009.
[28] Kets de Vries, M.: The Leadership Mystique. A User’s manual For the Human Enterprise. Pearson Education Limited. Great Britain, 2001.

[29] Kotsou, I.; Nelis, D.; Grégoire, J.; Mikolajczak,M.: Emotional Plasticity: Conditions and Effects of Improving Emotional Competence in Adulthood. Journal of Ap-plied Psychology, 2011, 96(4), 827-839. http://dx.doi.org/10.1037/a0023047

[30] Brodie, L. \& Porter, M.: Engaging distance and on-campus students in problem-based learning. European Journal of Engineering Education, 33(4), 2008, 433-444. http://dx.doi.org/10.1080/0304379 $\underline{0802253574}$

[31] Fernandez, Juan; Lopez, Ivan; Rubio, Ruben; Marco, Fernando: An assessment of behavioural variables im-plied in teamwork: an experience with engineering students on Zaragoza University. European Journal of Engineering Education, 2008, 34(2), 113-122. http://dx.doi.org/10.1080/03043790902748788

[32] Sanchez, I.; Neriz, L.; Ramis, F.: Design and application of learning environments based on integrative problems. European Journal of Engineering Education. 2008, 3(4), 445-452. http://dx.doi.org/ $\underline{10.1080 / 03043790802253616}$

[33] Brodie, L. \& Porter, M.: Engaging distance and on-campus students in problem-based learning. European Journal of Engineering Education, 33(4), 2008, 433-444. http://dx.doi.org/10.1080/0304379 $\underline{0802253574}$

[34] Lu, S.: Culture and Compliance Gaining in the Classroom: A Preliminary Investigation of Chinese College Teachers' Use of Behavior Alteration Techniques. Communication Education, 46(1), 1997, 10 28. http://dx.doi.org/10.1080/03634529709379070

[35] Brodie, L. \& Porter, M.: Engaging distance and on-campus students in problem-based learning. European Journal of Engineering Education, 33(4), 2008, 433-444. http://dx.doi.org/10.1080/03043790 $\underline{802253574}$

[36] Brunson, D. \& Vogt, J.: Empowering our students and ourselves: a liberal democratic approach to the communication classroom. 45(1), 1996, 73-83.

[37] Kreps, G. \& Lederman, L.: Using the case method in organizational communication education: Developing students' insight, knowledge, and creativity through experience-based learning and systematic debriefing. Communication Education, 34(4), 1985, 358-364. http://dx.doi.org/10.1080/03634528509378629

[38] Brunson, D. \& Vogt, J.: Empowering our students and ourselves: a liberal democratic approach to the communication classroom. 45(1), 1996, 73-83.

[39] Ferris, D.: Does error feedback help student writers? New evidence on the short- and long-term effects of writ-ten error correction. Published in Feedback in Second Language Writing. Contexts and Issues. Eds: Hyland, K. \& Hyland, F. Cambridge University Press. 2006, 81-104.

[40] Sugita, Y.: The impact of teachers' comment types on students' revision. ELT Journal, 60(1), Jan 2006, 34-41. http://dx.doi.org/10.1093/elt/cci079

[41] Frymier, A.; Shulman, G.; Houser, M.: The development of a learner empowerment measure. Communication Education, 1996 , 45(3),181-199. http://dx.doi.org/10.1080/03634529609379048

[42] Lu, S.: Culture and Compliance Gaining in the Classroom: A Preliminary Investigation of Chinese Col-lege Teachers' Use of Behavior Alteration Techniques. Communication Education, 46(1), 1997, 1028. http://dx.doi.org/10.1080/03634529709379070

[43] Kearney, P.; Plax, T.; Richmond, V.; McCroskey, J.: Power in the Classroom III: Teacher communication techniques and messages. Communication Education, 34(1), 1985, 19-28. http://dx.doi.org/ $\underline{10.1080 / 03634528509378579}$

[44] Garside, C.: Look who's talking: a comparison of lecture and group discussion teaching strategies in developing critical thinking skills. Communication Education, 1996, 45(3), 212-227. http://dx.doi.org/10.1080/03634529609379050

[45] Comstock, J.; Rowell, E.; Bowers, J.: Food for thought: teacher nonverbal immediacy, student learning, and curvilingearity. Communication Education, 44(3), 1995. http://dx.doi.org/10.1080/03634 $\underline{529509379015}$

[46] Neuliper, J.: A comparison of teacher immediacy in AfricanAmerican and Euro-American college class-rooms. Communication 
PAPER

CAN AND SHOUlD SOCIAL COMPETENCE BE TAUGHT TO ENGINEERS?

Education, 44(3), 1995, 267-277. http://dx.doi.org/10.1080/0363452 $\underline{9509379016}$

[47] Haleta, L.: Student perceptions of teachers' use of language: the effects of powerful and powerless language on impression formation and uncertainty. Communication Education. 45(1)1996, 16-27. http://dx.doi.org/10.1080/03634529609379029

[48] Comstock, J.; Rowell, E.; Bowers, J.: Food for thought: teacher nonverbal immediacy, student learning, and curvilingearity. Communication Education, 44(3), 1995. http://dx.doi.org/10.1080/03634 529509379015

[49] Frymier, A.; Shulman, G.; Houser, M.: The development of a learner empowerment measure. Communica-tion Education, 1996, 45(3),181-199. http://dx.doi.org/10.1080/03634529609379048

[50] McCroskey, J.; Sallinen, A.; Fayer, J.; Richmond, V.; Barraclough, R.: Nonverbal immediacy and cognitive learning: a crosscultural investigation. Communication Education, 45(3), 1996, 200-211. http://dx.doi.org/10.1080/03634529609379049

[51] Hazelton, P.; Malone, M.; Gardner, A.: A multicultural, multidisciplinary short course to introduce recently graduated engineers to the global nature of professional practice. European Journal of Engineering Education, 34(3), 2009. http://dx.doi.org/10.1080/030 43790903047503

[52] Saarinen, M. \& Kokkonen, M.: Tunneäly - kohti KOKOnaista elämää (Translated by P.L.: Emotional intelligence - towards a full life). WSOY, Juva 2003.

[53] Teven, J. \& McCroskey, J.: The Relationship of Per-ceived Teacher Caring with Student Learning and Teacher Evaluation. Communication Education, 46 (1), 1997, 1-9. http://dx.doi.org/10.1080/ $\underline{03634529709379069}$
[54] Moore, A.; Masterson, J.; Christophel, D.; Shea, K.: College teacher immediacy and student ratings of instruc-tion. Communication Education, 45(1) 1996, 29-39. http://dx.doi.org/10.1080/ 03634529609379030

[55] Frymier, A.; Shulman, G.; Houser, M.: The development of a learner empowerment measure. Communication Education, 1996, 45(3),181-199. http://dx.doi.org/10.1080/03634529609379048

[56] McCroskey, J.; Sallinen, A.; Fayer, J.; Richmond, V.; Barraclough, R.: Nonverbal immediacy and cognitive learning: a crosscultural investigation. Communication Education, 45(3), 1996, 200-211. http://dx.doi.org/10.1080/03634529609379049

[57] Lu, S.: Culture and Compliance Gaining in the Classroom: A Preliminary Investigation of Chinese College Teachers' Use of Behavior Alteration Techniques. Communication Education, 46(1), 1997, 10 28. http://dx.doi.org/10.1080/03634529709379070

[58] McMillan, J. \& Cheney, G.: The student as consumer: the implications and limitations of a metaphor. Communication Education, 45(1), 1996, 1-15. http://dx.doi.org/10.1080/03634529609379028

[59] Teven, J. \& McCroskey, J.: The Relationship of Per-ceived Teacher Caring with Student Learning and Teacher Evaluation. Communication Education, 46 (1), 1997, 1-9. http://dx.doi.org/10.1080/ $\underline{03634529709379069}$

\section{AUTHOR}

P. Lappalainen is with Aalto School of Science, P.O. Box 11000, FI-00076 Aalto, pia.lappalainen@aalto.fi.

Received 8 September 2011. Published as resubmitted by the author 27 September 2011. 